\title{
Generalization gradients along wavelength and angularity dimensions in pigeons following two differential training procedures ${ }^{1}$
}

MARTIN R. BARON AND CARL T. VACEK KENT STATE UNIVERSITY

Comparison of generalization gradients along dimensions of angularity and wavelength were made following differential training to (a) presence-absence of a vertical green line on $a$ white surround, and (b) presence-absence of $a$ vertical white line on a green surround. The angularity gradient was steeper for the group trained with the green line than the group trianed with the white one. Wavelength gradients were steep but not different for the two groups.

Evidence is available (Newman \& Baron, 1965) which indicates that control by angularity is established following differential training to presence-absence of a vertical white line on a green surround but is not established following differential training where a vertical white line on a green surround is positive and a red surround (with no line) is negative. This evidence has been interpreted (Baron, 1965) as indicating the existence of an attending hierarchy in pigeons in which color is perceived more readily than white line presence. One implication of this interpretation is that attention to the line (and control by angularity) might be greater if the line were colored than if it were white. More specifically, it would be expected that differential training to presence-absence of a green vertical line on a white surround would produce better control by angularity of the line than differential training to presenceabsence of a white vertical line on a green surround. Method

The Ss were 32 experimentally naive homing pigeons procured from a local supplier. The data from two of these (one from each group) were eliminated during the experiment because of procedural errors.

Two identical Skinner-type boxes described in Newman \& Baron (1965) were utilized.

Two In-Line Readout Display Cells (Industrial Electronic Engineers) furnished the stimuli appropriate to the two treatment conditions. A $1 / 4 \times 1$ in. line, in the center of the key aperture, could be made to appear at each of three positions: vertical $\left(0^{\circ}\right), 22-1 / 2^{\circ}$ counterclockwise from vertical, and $45^{\circ}$ counterclockwise from vertical. For one box, the cell presented a white line on a chromatic surround; for the other box, the cell presented a chromatic line on a white surround. Wavelength values of $555 \mathrm{~m} \mu, 585 \mathrm{~m} \mu$, and $626 \mathrm{~m} \mu$ were available in both cells.

A masking white noise was continuously presented through a speaker mounted in the ceiling of each box. Responses were recorded on four-digit counters.

The Ss were reduced to $75 \%$ of their ad lib weights, and were maintained at this weight with a tolerance of $\pm 10 \mathrm{~g}$, throughout the experiment. Water was available in individual home cages.

On Day 1, Ss were randomly assigned to treatment groups and were magazine and key peck trained by successive approximations. For each treatment group, the stimulus which would be the S+ during differential training appeared continuously on the key. Each S was allowed 100 continuously reinforced responses, 50 on Day 1 , and an additional 50 on Day 2.

On Days 3-13, the Ss underwent differential training. For Group 1 the S+ consisted of a $555 \mathrm{~m} \mu$ vertical line on a white surround and the $S-$ consisted of a white surround; for Group 2 the $S+$ was a white vertical line on a $555 \mathrm{~m} \mu$ surround and the $\mathrm{S}-$ was a 555 $\mathrm{m} \mu$ surround. Reinforcements, available for $3 \mathrm{sec}$, were programmed on a VI schedule with a $1 / 2 \mathrm{~min}$ mean interval for the first day of training and a 1 min mean interval for the remaining 10 training days. The daily sessions for both groups consisted of 32 $55 \mathrm{sec}$ periods of S+ presentations and $3215 \mathrm{sec}$ periods of $\mathrm{S}-$ presentations. Periods of $\mathrm{S}+$ and $\mathrm{S}-$ were alternated in an A B B A B A A B sequence.

On Days 14-16, all Ss were provided warm up sessions followed by generalization tests along the dimensions of wavelength and angularity. A warm up session consisted of six $45 \mathrm{sec}$ S+ presentations alternated with six $45 \mathrm{sec} S-$ presentations; two randomly spaced reinforcement periods were provided during each St presentation. The generalization testing commenced immediately after the warm up trials. For all Ss there were nine test stimulus combinations: Group 1 was presented the three angular orientations in three wavelengths, all on a white surround; Group 2 was presented the three angular orientations of the white line paired with the three wavelengths of the surround. Each of the nine stimulus presentations lasted $45 \mathrm{sec}$, and was administered nine times each day in a prearranged counterbalanced order. Each replication of eight Ss began the test with a different stimulus and was presented with a different order of test stimuli. For any $S$, the order of test stimuli was the same for all three days of test. No reinforcements were given during generalization tests, and no black- 


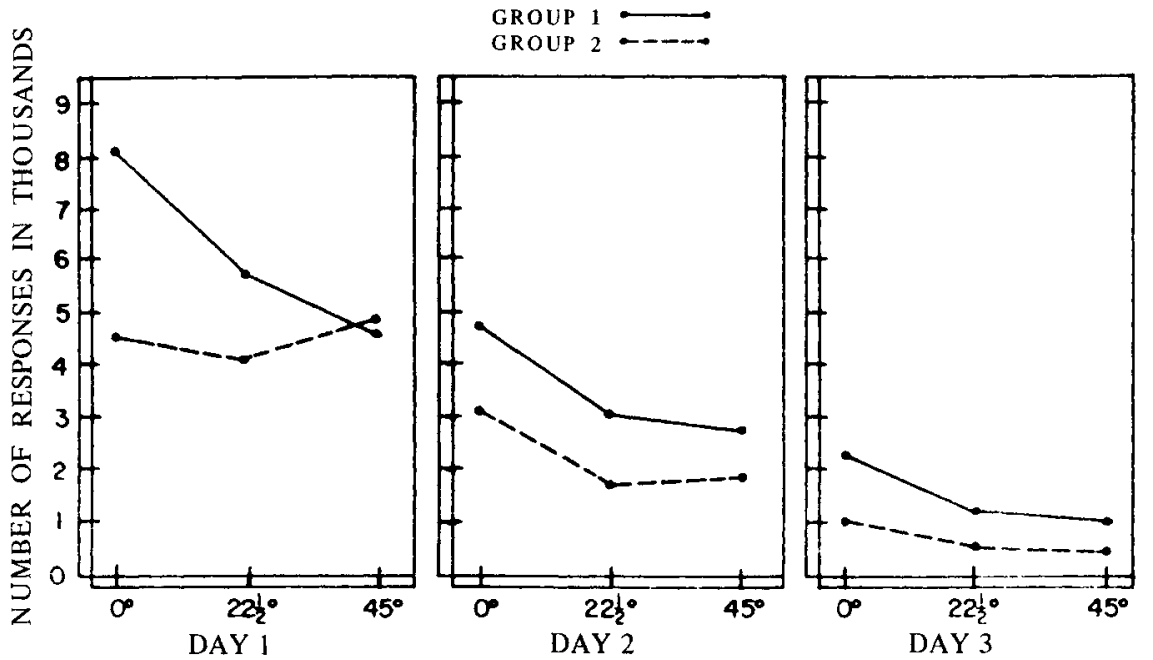

DEGREES OF ANGULARITY
Fig. 1. Total number of responses to angular orientations on each day of testing for all wavelengths and Ss. out periods were provided between presentations of test stimuli.

After the first 16 Ss had completed the entire course of the experiment, the two display cells were interchanged from one Skinner box to the other. Results

An overall analysis of variance showed a significant interaction of groups by angular orientation $(F=8.38$, $\mathrm{df}=2 / 56, \mathrm{p}<.01$ ); as expected, control by angularity was significantly greater with the green line on the white surround than with the white line on green surround.

Because of a significant triple interaction of groups by angular orientation by days of test $(F=5.65$, df $=4 / 112, p<.001$ ), which demonstrates that the difference in angularity gradient slopes between the two groups changed over test days, the data were examined separately for each day. Inspection of Fig. 1 shows that angularity control was different for the two groups only on Day 1. Separate analyses of variance for each day confirm this observation; the interaction of groups by angular orientation was significant only on Day 1 ( $F=9.74$, df $=2 / 56, p<.001)$, and failed significance at the .05 level on Days 2 and 3 . In addition, Fig. 1 shows a flattening of the angularity gradients for Group 1 from Day 1 to Day 2, while the gradient for Group 2 is steeper on Day 2 than Day 1. Separate analyses of variance for each group for each day showed a significant effect of angularity for Group 1 on all days of test with each $p<.01$, while Group 2 manifested a significant effect $(p<.01)$ only on Day 2 .

Wavelength generalization gradients were also ob- tained; they were steep and reliable for both groups combined $(F=171.63, \mathrm{df}=2 / 56, \mathrm{p}<.001)$. There was no difference in steepness of gradients for the two groups; moreover, the slopes were similar on the three test days.

Discussion

The greater angularity control obtained with a green line on a white surround than with a white line on a green surround is consistent with the results of two separate studies. Butter \& Guttman (1957) found a relatively flat (but reliable) angularity gradient employing a white line on a black surround, while Butter (1963) obtained a steep angularity gradient with a green line on a black surround. The results of the present study, considered along with the results of these two studies, tend to support the notion that stimulus control in pigeons is influenced by an attending hierarchy in which color is relatively high.

\section{References}

BARON, M. R. The stimulus, stimulus control, and stimulus generalization. In D. I. Mostofsky (Ed.), Stimulus generalization. Stanford: Stanford Univer. Press, 1965.

BUTTER, C. M. Stimulus generalization along one and two dimensions with pigeons. J. exp. Psychol., 1963, 65, 339-346.

BUTTER, C. M., \& GUTTMAN, N. Stimulus generalization and discrimination along the dimension of angular orientation. Amer. Psychologist, 1957, 12, 449 (Abstract).

NEWMAN, F. L., \& BARON, M. R. Stimulus generalization along the dimension of angularity: a comparison of training procedures. J. comp. physiol. Psychol., 1965, 60, 59-63.

Note

1. This paper is based upon a thesis submitted by the second author in partial fulfillment of the requirements for the M. A. degree at Kent State University, 1965. 